\title{
DEFORMATION RESPONSE OF DUAL PHASE STEEL IN STATIC AND DYNAMIC CONDITIONS
}

UDC: 539.374

Original scientific paper

https://doi.org/10.18485/aeletters.2019.4.2.1

\author{
M.R. Sunil Kumar ${ }^{1 *}$, Eva Schmidova ${ }^{1}$ \\ ${ }^{1}$ University of Pardubice, Faculty of Transport Engineering, Pardubice, Czech Republic
}

\begin{abstract}
:
In this work, strength and plastic deformation effect of the dual phase steel are analysed in the static and dynamic conditions. Since the dual phase steel is extensively used in the outer body parts of the automotive vehicles, their dynamic strength and plastic strain energy absorption during the crash are essential. Dynamic strength of the dual phase steel is examined using the pendulum impact hammer tester machine. Spread of the plastic strain during the crash is an important factor for the energy absorption to passive safety, which is examined using the local hardness measurement using the Vickers hardness and local indentation yield strength is calculated using the cylindrical indenter and obtained force-depth results are analysed using the Hencky theory for the plane strain indentation. Further, tested samples are observed using the scanning electron microscopy for the fracture response after the static and dynamic tests.
\end{abstract}

ARTICLE HISTORY Received: 03.04.2019. Accepted: 31.05.2019. Available: 30.06.2019.

\section{KEYWORDS}

Dual phase steel, Plastic deformation, indentation, Fracture response and Hencky theory

\section{INTRODUCTION}

Increased demand for fuel efficiency and environmental concern forced the automotive industry to reduce the gross weight of the vehicle. This factor forced the steel manufacturing industry to develop new high strength steel which has higher strength and lower weight compared to normal steel. Different types of the high strength steels are being used in the automotive industry for several decades, especially for outer body components. The usage of the dual phase steel for the outer body parts is constantly increasing. In this work, the HCT 450X ferritic-martensitic dual phase steel is used for analysis of strength and plastic deformation ability in static and dynamic conditions. Along with the ferritic-martensitic structure, it has manganese to increase the strength and stabilize the austenite, silicon to enhance the ferrite transformation. The dual phase steel examined here is extensively used for the outer body parts of the automotive applications. Since the outer body parts are exposed to the environment and first form of resistance during the crash and minor accidents, these steels are required to have good corrosion resistance ability, high strength to weight ratio, better weldability, high formability and high strain energy. The higher strain energy is one of the important factors to be considered during the passive safety of automobiles. Presence of higher martensite content increases the strength of the DP steel but further increase in the content of martensite reduces the formability [1-3].

Huang et al. [4] have examined the dual phase strain hardening behaviour and their grain structure changes. Ghassemi-Armaki et al. [5] have worked on 
the deformation behaviour of martensite and ferrite in the dual phase steel.

In this work, static and dynamic strengths, as well as plastic strain spread of the dual phase steel are examined. The strength of the dual phase steel is examined in static and dynamic conditions using the universal tensile testing machine and dynamic pendulum impact tester machines. The spread of the plastic deformation is the key factor in deciding the strain energy absorption during the crash, which is analysed by measuring the hardness and microindentation yield strength after the testing of samples. Variation of the local hardness and local indentation yield strength are important parameters to analyse the spread of the plastic strain after the static and dynamic tests. Local hardness is measured using the Vickers indenter and local indentation yield strength is measured using the cylindrical indenter and evaluated from the Hencky theory for plane strain indentation.

\section{MATERIALS AND METHODS}

Table 1 shows the chemical composition of the examined dual phase steel HCT 450X and Fig.1 shows the SEM image of the dual phase steel having ferritic-martensitic phases. Image analysis is used to obtain quantitative data about the phase ratio.

To find out the strength of the dual phase steel in the static conditions, the standard static tensile test has been performed using the Zwick universal tensile testing machine; the used samples including holder are presented in Fig.2 a) and b) respectively. Forcedisplacement graph yield strength and ultimate tensile strength are recorded in computers.

Table 1. Chemical composition weight percentage of dual phase steel

\begin{tabular}{|c|c|}
\hline Element & Weight percentage \\
\hline $\mathrm{C}$ & 0.130 \\
\hline $\mathrm{Mn}$ & 1.933 \\
\hline $\mathrm{Si}$ & 0.200 \\
\hline $\mathrm{P}$ & 0.022 \\
\hline $\mathrm{S}$ & 0.002 \\
\hline $\mathrm{Cr}$ & 0.187 \\
\hline $\mathrm{Ni}$ & 0.018 \\
\hline $\mathrm{Cu}$ & 0.017 \\
\hline $\mathrm{Ti}$ & 0.026 \\
\hline $\mathrm{Al}$ & 0.022 \\
\hline
\end{tabular}

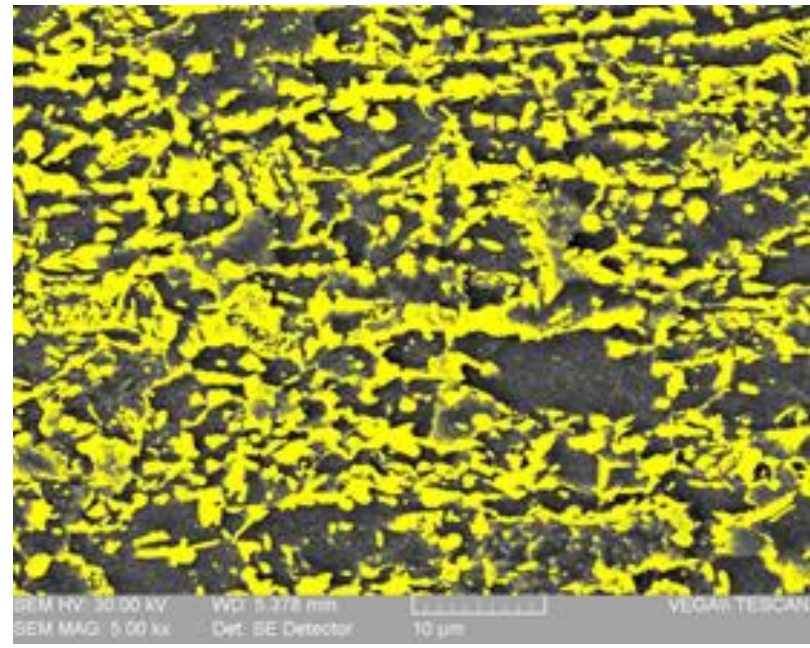

Fig.1. Dual phase steel SEM image

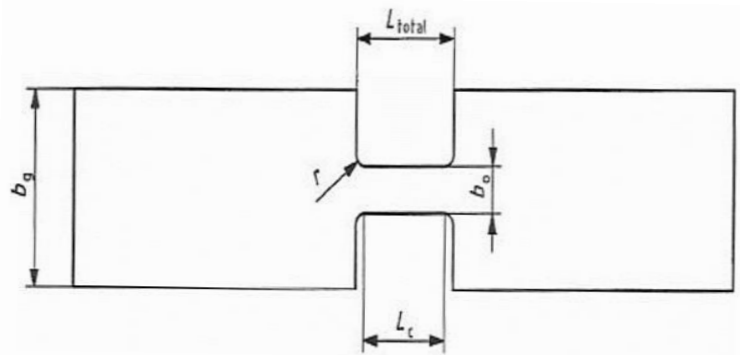

(a)

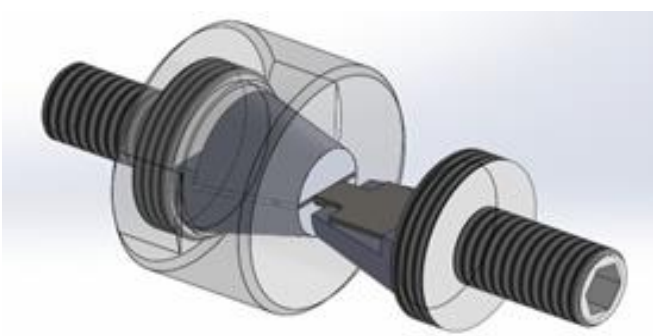

(b)

Fig.2. (a) Test specimen for dynamic impact test and (b) special holder

\subsection{Strength test of the dual phase steel in the static and dynamic conditions}

The dynamic strength test of the dual phase steel is performed in the Zwick pendulum impact hammer tester. The sample dimensions are $b_{g}=15 \mathrm{~mm}, b_{0}=5$ $\mathrm{mm}, \mathrm{L}_{\text {total }}=9 \mathrm{~mm}, \mathrm{~L}_{\mathrm{c}}=5 \mathrm{~mm}, \mathrm{r}=2 \mathrm{~mm}$. A special type of holder is designed in the laboratory to perform the impact test for the dual phase steel in pendulum impact tester. 


\subsection{Plastic Deformation of the dual phase steel after the static and dynamic test}

Since the dual phase steels are mainly designed for the automobile outer body parts, energy absorption during the collision is the key factor. The strain energy absorption during the collision is dependent on the plastic deformation and strain hardening ability of the material. To approximate the residual hardening and spread of the plastic deformation after the static test, Zwick hardness testing machine is used. After the tensile test, the specimen is cut in the longitudinal direction then ground and polished. The hardness of the sample is measured from the fractured end to the unaffected end. To see the fracture response in the sample, images are taken in the optical and electron microscopes at different magnifications to analyze the grain structure morphology. Hardness is measured, starting from the fractured end using the Vickers method. Graphical representation of the hardness measurement is shown in Fig.8.

\subsection{Determination of the yield strength using macro-indentation}

To find out the better distribution of plastic deformation and residual hardening effect of the fracture, the macro-indentation technique is used with $0.5 \mathrm{~mm}$ diameter cylindrical indenter. Based on the elastic-plastic transition of the curve in the forcedepth graph, yield strength is calculated [6].

The indication force level at the transition from elastic to plastic state is calculated using the simple curve deviation technique. The Hencky theory for plane strain indentation slip is used to calculate the real yield strength. The ratio of indentation yield strength to normal yield strength is 2.57 according to Hencky equations for the plane strain indentation [7, 8]. Pressure relative to shear yield stress is $P_{\text {indent }} / 2 \mathrm{k}$ $=2.57$. Calibration was performed to get precise results for tested steel by the standard tensile test of uninfluenced steel. Fig. 3 shows the calculation of elastic-plastic transition force using the force-depth indentation curve.

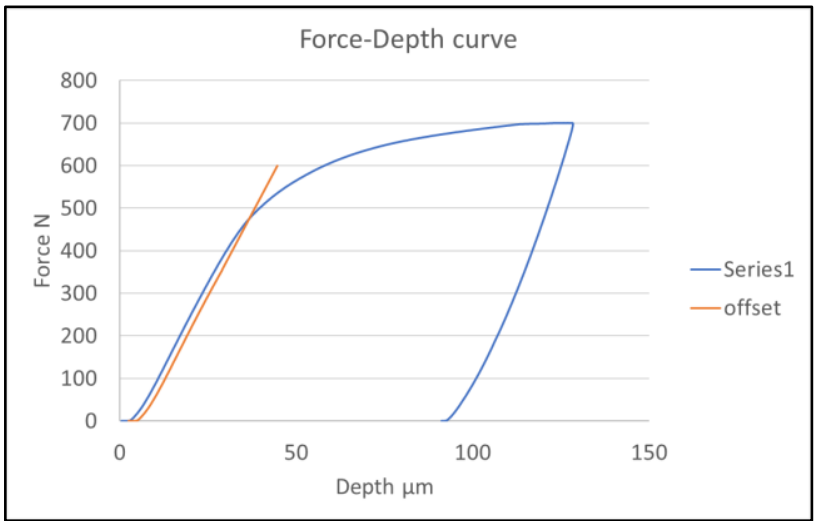

Fig.3. Force-depth curve from indentation test

\section{RESULTS AND DISCUSSIONS}

\subsection{Strength of the dual phase steel}

Fig.4 shows the static test results of the dual phase steel performed using the universal tensile testing machine. The average yield stress of the dual phase steel is about $670 \mathrm{MPa}$ and the average ultimate tensile stress is about $770 \mathrm{MPa}$. The values clearly indicate the higher strength of the dual phase steel compared to interstitial free steel, bake hardened and high strength steel but still lower than TWIN and advanced high strength steel.

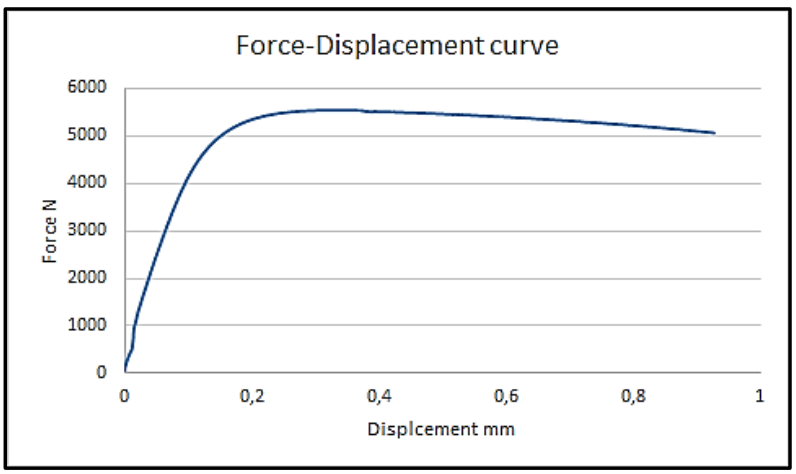

Fig.4. Force-displacement graph for the static tensile test

Fig.5 shows the dynamic impact test results of the dual phase steel performed using the pendulum hammer impact tester. The average ultimate tensile strength in dynamic conditions is about $1100 \mathrm{MPa}$. The value of UTS in dynamic conditions are considerably higher than in the static conditions. A special type of holder is designed for the smaller sample size and to reduce the vibrations. The vibration effect of the dynamic impact test is 
removed using the polynomial equations of the higher order and the sample having the minimum of three waves are selected based on the literature review.

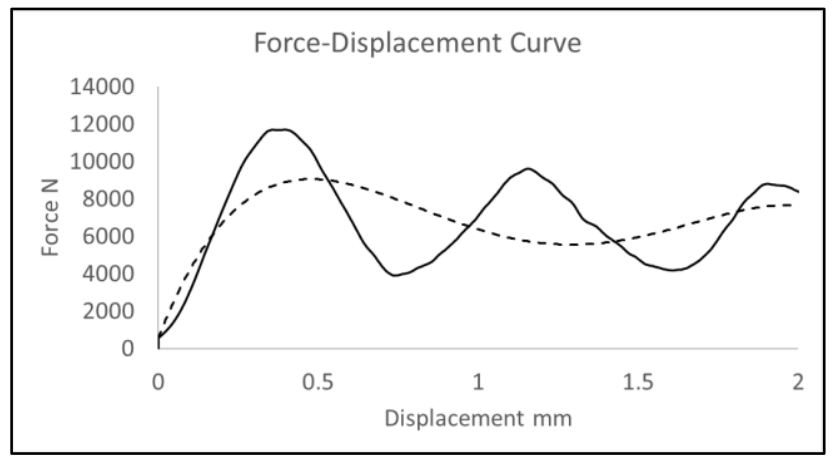

Fig.5. dynamic test results from the impact pendulum tester

\subsection{Plastic deformation of dual phase steel}

Fig.6 shows the SEM image of the fractured surface of the dual phase steel after the static tensile test. Fractured surface clearly indicates the ductile fracture mode with coalescence of microvoids.

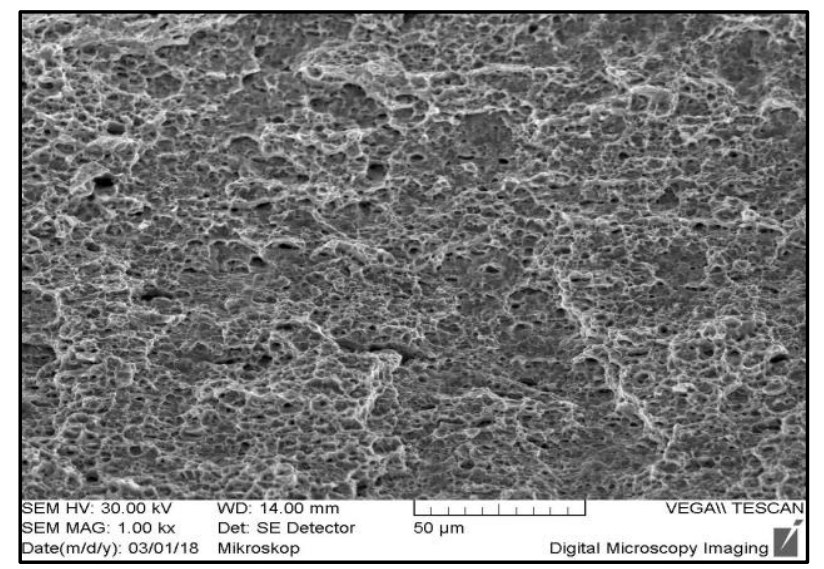

Fig.6. SEM image of the fractured surface after static test

Fig.7 shows the SEM image of the fractured surface of the dual phase steel after the dynamic impact test. A clear ductile fracture can be seen even after the impact test with the presence of the transverse cracks. It has pointed on the increased sensitivity of the steel to internal imperfections. Important results towards the current application are the fact, that even at the maximal tested strain rate of 1060 /s, the ductile mechanism was retained. The real state of metallurgy quality didn't lead to the transition to brittle fracture mode. The critical issue from this point of view can be the presence of brittle, sharp secondary phases and imperfections, e.g. carbonitrides, complex oxides. Sulfides are not commonly critical. Except for the case intensive plastic deformation after the hot or cold rolling and so the creation of sharp tip at interphase with the matrix. All the observed critical parts were checked and based on that it can be stated that the tested steel has no tendency to transition fracture behaviour inside the analyzed range of the strain rate. The energy consumption is driven much more by the spread of plasticity, restricted according to the dynamic loading conditions.

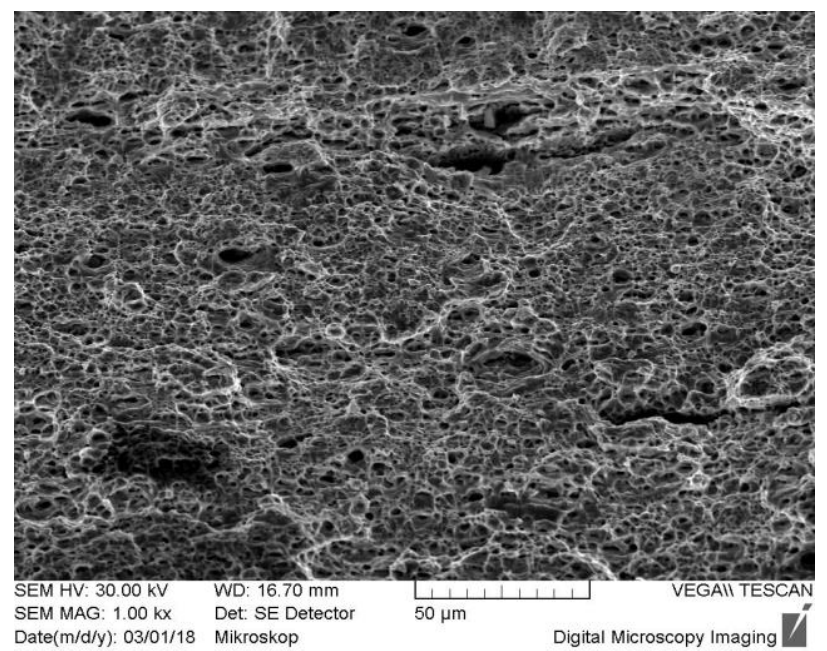

Fig.7. SEM image of the fractured surface after dynamic test

While the hardness as a material parameter can be employed as comparative information of UTS, it doesn't reflect the complex transition micro versus macro-plasticity in steel. A complex elastic-plastic response as comprehensive information about the material response to loading is required to real interpretation of process, which took place during static versus dynamic loading. The local yield strength must be evaluated in tight connection with microstructure characterization of the loading volume of steel.

\subsection{Hardness values}

Fig. 8 shows the hardness values measured in hardness testing machine using the Vickers indenter. The graph is constructed based on the hardness 
values from fractured end to the unaffected end for both static and dynamic samples. High hardness values are being recorded near the fractured end and decrease as it moves towards the unaffected end. Plastic deformation is not the same for static and dynamic conditions, which can be identified using the hardness values. In the case of the static sample, the spread of the plastic deformation is large and record comparatively low hardness values. The reasons for the large plastic deformation in the static conditions are the availability of enough time and low strain rate during the static tensile test.

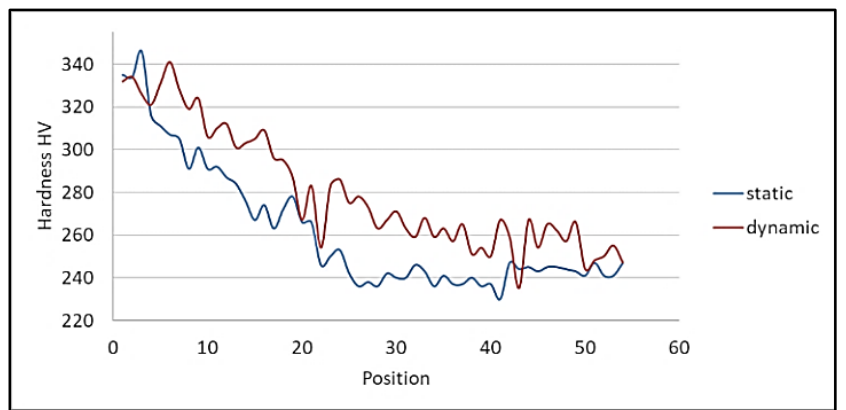

Fig.8. Hardness distribution from fractured end to unaffected end

In the case of dynamic samples, the spread of plastic deformation is limited only near to the fractured end and large portion of the sample is unaffected by the plastic deformation, which is concluded by the slow gradual decrease in the hardness values just after one or two measurements.

Though the relation between hardness and residual strain is slightly complicated the fact is that hardness increases with the increase of residual strain $[9,10]$. Despite the complicated relation still, hardness is a suitable measurement for the local residual strain distribution.

\subsection{Macro-indentation results for the local yield strength}

Fig.9 shows the indentation yield strength measurement of the dual phase steel sample after the static tensile or dynamic impact test. Three indentation readings are measured close to the fractured end with a gap of $1 \mathrm{~mm}$ each. Another three hardness measurements are made in the unaffected end to have a better comparison of hardness values. The force-depth graph of the unaffected area is obtained from the indentation using $0.5 \mathrm{~mm}$ cylindrical indenter for the static sample. From the force-depth graph, the transition of the curve from elastic to plastic region is almost identical and follow the same pattern. The average value of the force from elastic to plastic deviation is about 310 N. Fig.10 shows the force-depth graph near the fractured end obtained from the indentation rest using $0.5 \mathrm{~mm}$ cylindrical indenter. From the force-depth graph it is clear that the transition from elastic to plastic behaviour is not the same for all the curves. The reason for the different curve response is attributed to the varying plastic deformation during the static tensile test. The values of force from elastic to plastic deformation is about $450 \mathrm{~N}, 320 \mathrm{~N}$ and $255 \mathrm{~N}$ respectively from the fractured end. Using Hencky theory for plane strain indentation slip it is possible to calculate the approximate yield strength of the sample. Values of the yield strength are shown in Table 2 [11-13].

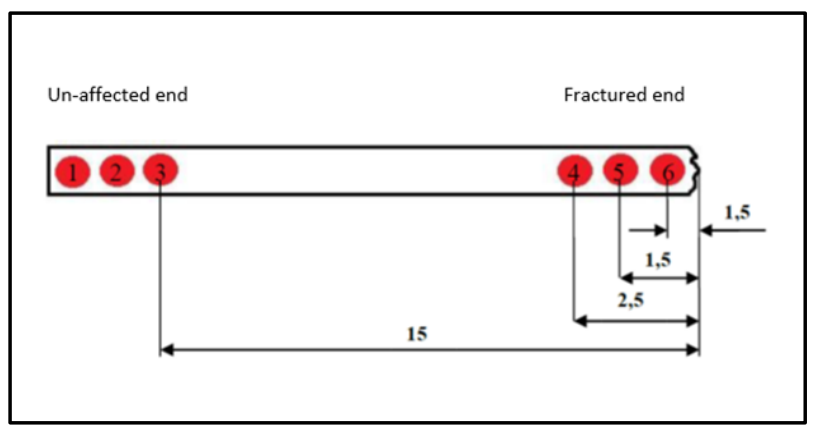

Fig.9. Yield strength measurement positions using indentation technique [14]

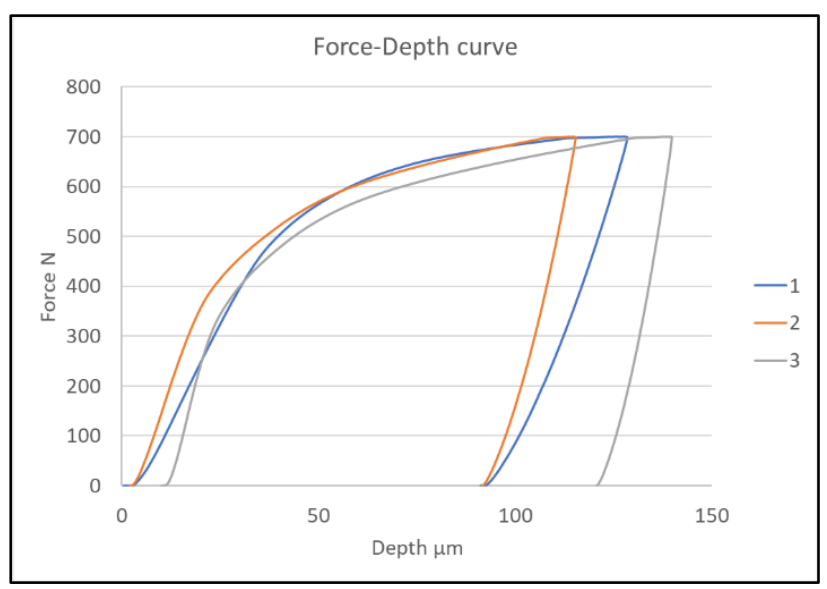

Fig.10. Force-depth curve for the static sample from the fractured end 
Fig.11 shows the force-depth graph near the fractured end obtained from the indentation test after dynamic impact test. Compare to the results from the static sample, these dynamic sample results are considerably different. Force values from elastic to plastic transition are $420 \mathrm{~N}, 341 \mathrm{~N}$ and 300 $\mathrm{N}$, respectively. The sudden drop of the elasticplastic transition force value from $420 \mathrm{~N}$ to $341 \mathrm{~N}$ indicates the shorter spread of the plastic deformation during the dynamic impact test. The local yield strength is calculated using Hencky theory for plane strain indentation and shown in Table 2 . Determination of the local yield strength is helpful in further confirmation of the area of plastic strain after the static and dynamic tests. The higher yield strength near the fractured area indicates the higher strain hardening effect. Just like hardness, the yield strength is also the indicative parameter for the spread of the plastic strain.

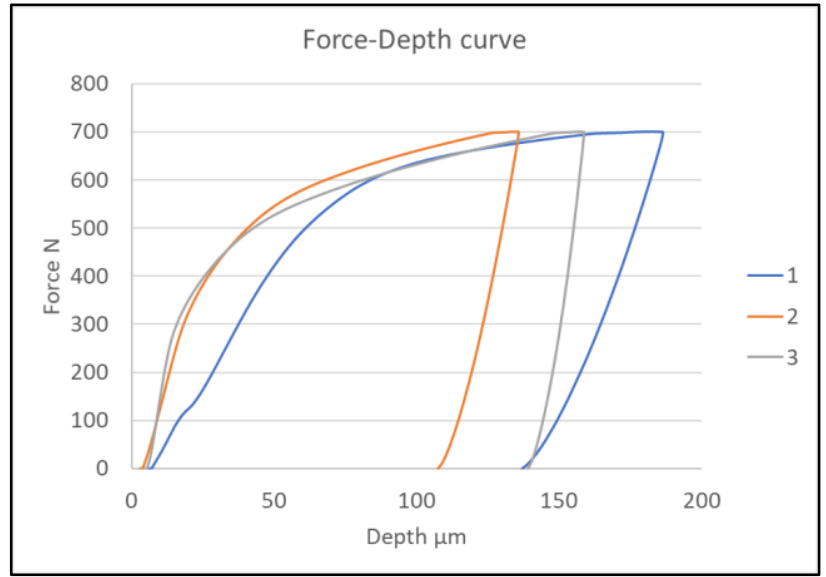

Fig.11. Force -Depth curve for the dynamic sample from the fractured end

Table 2. Local indentation yield strength for static and dynamic samples

\begin{tabular}{|c|c|c|c|c|}
\hline Position & 1 & 2 & 3 & $\begin{array}{c}\text { Unaffected } \\
\text { area Avg. }\end{array}$ \\
\hline Static & 891.98 & 634.30 & 505.46 & 614.48 \\
\hline Dynamic & 832.52 & 675.92 & 595.56 & 614.48 \\
\hline
\end{tabular}

As stated above, the obtained results have shown the significant influence of the strain rate on the capability of tested steel to spread the plasticity. The mentioned process is a crucial effect on energy consumption. The strengthening process, together with residual stress level is substantially influenced by the local stress-strain state. That means, it should be distinguished in all the outcomes the material versus sample dimensions influence. Because of that, the performed analyzes must be considered as comparative. Obtained data about the spread of plasticity present also useful information about the influence of real sample shape and dimensions. Even in full accordance with valid standards, there is some plastic flow outside the measured area. In the case of restricted part for testing the mentioned effect is not negligible.

\section{CONCLUSION}

Comparative analyses of the dual phase steel after loading at the static and dynamic conditions were performed. Standard hardness measurement followed by the indentation tests and evaluation through the Hencky plane strain theory showed significant sensitivity to strain rate. Observation of the fractured sample in the Scanning electron microscopy for the type of fracture response proved the stabile fracture mode. Following conclusions are made based on the above observation:

1. The dynamic strengthening of the experimental dual phase steel at an average strain rate $1060 \mathrm{~s}^{-1}$ is about $43 \%$.

2. Spreads of the plastic deformation are considerably different in static and dynamic conditions, large plastic strain spread can be observed in the static test.

3. The spread of the plastic deformation is also confirmed using the Vickers hardness and shows a high value near the fractured end decreases gradually towards the un-affected end.

4. Both in the static and dynamic fracture, the mode of fracture is ductile, which means even at higher loading the material is managed the ductile fracture. 5. The local indentation yield strength helps in further identifying the spread of the plastic deformation and values shows the difference in the hardening effect. An optimized methodology using different positioning of the measured points is necessary for detailed evaluation of discussed processes by used methodology.

\section{ACKNOWLEDGEMENT}

This study has been accomplished by support of the Grant No: SGS-2018-023. 


\section{REFERENCES}

[1] M. Mazinani, Deformation and fracture behaviour of a low-carbon dual-phase steel (PhD Thesis), The faculty of graduate studies (Metals \& Materials Engineering). The University of British Columbia, Canada, 2006.

[2] B.-C., Hwang, T.-Y. Cao, S.Y. Shin, S.-H. Kim, S.-H. Lee, S.-J. Kim, Effects of ferrite grain size and martensite volume fraction on dynamic deformation behaviour of $0.15 \mathrm{C}-2.0 \mathrm{Mn}-0.2 \mathrm{Si}$ dual phase steels. Materials Science and Technology, 21(8), 2005: 967-975. https://doi.org/10.1179/174328405X47609

[3] N.D. Beynon, S. Oliver, T.B. Jones, G.Fourlaris, Tensile and work hardening properties of low carbon dual phase strip steels at high strain rates. Materials Science and Technology, 21(7), 2005: 771-778.

https://doi.org/10.1179/174328405X41038

[4] T.T.Huang, R.B. Gou, W.J. Dan n, W.G. Zhang, Strain-hardening behaviours of dual phase steels with microstructure features. Materials Science \& Engineering: A, 672, 2016: 88-97. https://doi.org/10.1016/i.msea.2016.06.066

[5] H. Ghassemi-Armaki, R. Maaß, S.P. Bhat, S. Sriram, J.R. Greer, K.S. Kumar, Deformation response of ferrite and martensite in a dualphase steel. Acta Materialia, 62, 2014: 197211.2014. https://doi.org/10.1016/j.actamat.2013.10.001

[6] W.C. Oliver, G.M. Pharr, An improved technique for determining hardness and elastic modulus using load and displacement sensing indentation experiments. J. Mater. Res., 7(6), 1992: 1564-1583.

https://doi.org/10.1557/JMR.1992.1564
[7] P. Hanus, E. Schmidová, M. Schmid, The possibility of evaluating the yield strength through indentation, Conference: Metal 2015, 3-5 Jun, 2015, Brno, Czech Republic, EU.

[8] K. Bowman, Mechanical behaviour of Materials. John Wiley and sons Inc. New Jersey, USA, 2004.

[9] K. Tosha, Influence of Residual Stresses on the Hardness Number in the Affected Layer Produced by Shot Peening. $2^{\text {nd }}$ Asia-Pacific Forum on Precision Surface Finishing and Deburring Technology, Seoul, Korea, July, 2002.

[10] P. Zhang, S.X. Li, Z.F. Zhang, General relationship between strength and hardness. Materials Science and Engineering A, 529, 2011: 62-73.

https://doi.org/10.1016/i.msea.2011.08.061

[11] J. Luo, J. Lin: A study on the determination of plastic properties of metals by instrumented indentation using two sharp indenters. International Journal of Solids and Structures, 44, 2007: 5803-5817. https://doi.org/10.1016/i.ijsolstr.2007.01.029

[12] J. Luo, J. Lin, T.A. Dean: A study on the determination of mechanical properties of a power law material by its indentation forcedepth curve. Philosophical magazine, 86(19), 2006: 2881-2905. https://doi.org/10.1080/14786430600640528

[13] B.L. Ennis, C. Bos, M.P. Aarnts, P.D. Lee, E. Jimenez-Melero, Work hardening behaviour in banded dual phase steel structures with improved formability. Materials Science \& Engineering: A, 713, 2018: 278-286.

https://doi.org/10.1016/i.msea.2017.12.078

[14] P. Ondráček, Study of dynamic strength of dual phase steel for car body: Diploma thesis. Jan Perner Transport Faculty, The University of Pardubice, Czech Republic, 2018. 